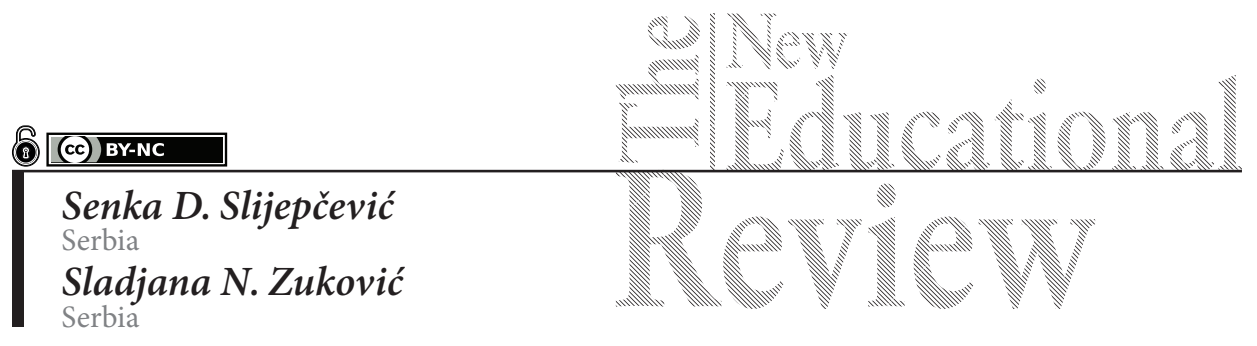

\title{
School Counsellor-Teacher Collaboration in Student Counselling'
}

DOI: 10.15804/tner.2021.63.1.19

\begin{abstract}
An active collaboration with teachers is a prerequisite of system based approach to school counselling. The objective of the research was examining the experiences of school counsellors regarding collaboration with teachers in the domain of student counselling in the school setting in Serbia. This research applied a pragmatist qualitative approach using a semi-structured interview. Participants were 81 elementary school counsellors (pedagogues). The results show that teachers are generally open for collaboration during student counselling. Teachers' acceptance of advice depends on their personality and classroom management style. Conclusions offer recommendations for improving the partnership relations as a basis for effective student counselling.
\end{abstract}

Key words: Collaboration, counselling, partnership, school counsellor, teacher

\section{Introduction}

Ecosystem theory of personality development is a basis of school counselling philosophy, which implies that it is necessary to acknowledge and take care of

1 The research plan was designed for the wider research on school counselling. For the purposes of this paper, a segment related to the collaboration with teachers in student counselling was used. The findings of this particular research were presented at $2^{\text {nd }}$ International conference on Advanced Research in Education, Teaching and Learning held in Berlin, Germany from 20-22 ${ }^{\text {nd }}$ March, 2020. 
the surroundings in which a child is developing in order to adequately influence their physical and psychological development. General school climate, school policies, as well as an understanding of the school's role in student development, has the crucial influence on the overall organization and content of school counselling. Drawing from this systemic view, school counsellors have a responsibility to bring a collaborative and holistic wellness perspective to their counselling practice (Arthur \& Collins, 2010, as cited in Dixon \& Chiang, 2019). Therefore, in order to maximize the effects of school counselling, it is necessary to achieve participatory action by all subjects in a particular school context, which implies their close cooperation and supportive relationship (Zuković, 2017). In fact, teamwork, based on collegiality (Bovbjerg, 2006; Shah, 2012) enriches everyone who participate in it, creates opportunities for learning and information exchange, and enables illumination of the problem and analysis of specific situations from a number of different professional fields and points of view. This means that school counselling should be understood as the process that permeates all spheres of the educational work (Zuković, 2017), and involves collaboration with teachers which is essential for providing the best services for students (Clark \& Amatea, 2004). The competencies of school counsellors for the development of the pedagogical relationships with students, parents and colleagues are crucial for counselling to truly be a helping and understanding relationship (Juul \& Jensen, 2017; Zuković \& Slijepčević, 2019). Such an approach allows the development of partnership as a collaborative relationship based on trust as well as shared responsibility in the counselling (Vernon \& Kottman, 2009).

The literature (Zuković, 2017) points out that school counselling is made up of three processes that are very often intertwined - direct counselling with students, consulting, and coordinating. These processes imply that the counselling program should be an integral part of the school curriculum. This includes addressing both the needs of the school as a whole, and of all the schools' subjects individually. However, the fact is that school counselling in Serbia is a very broad area of activity for which there is no well-defined work program (Zuković \& Slijepčević, 2020). It is mainly based on general theoretical concepts and guidelines on efficient counselling. This often results in different practices. They may be effective on their own but they often do not fit into the contemporary concept of school development. Thus, for example, the "traditional ethos of school counselling" is often present in our schools. It is an individual model of counselling based on the concept that a problem "resides within the individual" (Bor et al., 2002). The application of such a model causes the individual to be the main focus without paying enough attention to the importance of involving significant others. Also, such practice 
does not provide sufficient opportunities to reflect the effects of counselling work on improving the educational work and school climate. Therefore, it is preferable to gravitate towards a model that is characterized by the "ethos of systemic school counselling" (Bor et al., 2002). An integrative model in which a particular problem is viewed as part of a broader context, counselling is directed to the system as a whole and to the relationships in a particular system environment. Such approach contributes to the understanding of relationships, that could potentially be a source of a problem, on different levels (family-school, school-student, family-child) and to directing specific interventions towards affecting those levels. In these cases, an adequate reaction of school staff, especially teachers who have direct contact with students on a daily basis, is very important.

Since some new roles of teachers require them to react to different needs and situations (Przybylska, 2011), they are expected to be the initiators of different preventative and interventional activities. It is important to note that one of the difficulties in school counselling resides in the wrong or inadequately formed beliefs of teaching staff about the purposes of counselling. Specifically, teachers sometimes perceive counselling negatively, believing that students use it as a way to leave classroom and avoid some teaching activities. On the other hand, there is a phenomenon that teachers expect school counsellors to solve their problems in establishing relationships with students (especially when it comes to discipline in class) (Zuković, 2017). In spite of the fact that working on changing students behavior generally requires a change in teachers behavior, teachers often show resistance to active involvement in the counselling process. Such beliefs can prevent a collaborative relationship between counsellors and teachers. That is why it is very important to educate teachers about counselling, the importance of collaboration, joint action, and their active participation in the process of counselling with students (Chan, 2000; Vernon \& Kottman, 2009).

\section{General Background of Research}

Contemporary aspirations in pedagogical science are aimed at emphasizing the importance of establishing partnerships between all stakeholders relevant to the education, upbringing and overall development of the child's personality (Bray, 2001). Considering many benefits of collaboration during the counselling process, it seems important to examine the actual presence and the quality of this collaboration. Although school counselling should strive for an integrative model, counselling practice often comes down to discussions between counsellors and students. Therefore the involvement of teachers is not sufficiently present in practice. Accordingly, a draft of this research was developed to examine the practical experiences of school 
counsellors on the frequency and quality of collaboration with teachers in the field of student counselling. On this basis, the following research tasks were set:

1. To what extent and in which situations school counsellors involve teachers in the process of counselling with students?

2. What is the school counsellor's opinion about the teacher's openness to cooperation and willingness to accept potential suggestions?

\section{Methodology of Research}

A pragmatist qualitative research was applied. This phenomenological approach is aimed at understanding the phenomena under examination, as well as looking at the respondents' self-perception about their own practice (Eatough \& Smith, 2008; Savin-Baden \& Major, 2012). The data was collected using a semi-structured interview.

\section{Sample and Research Instrument}

The sample consisted of 81 primary school counsellors (47 participants from urban/suburban schools and 34 from rural schools) from Vojvodina, Serbia. It was a convenient sample.

The questions in the created Interviewing Protocol were formulated in advance in a way that ensures that the interview flow follows the assigned research tasks, but at the same time leaves room for the respondents to express their opinions freely. The respondents were asked the following questions: Do you involve teachers in the counselling process? How open are teachers to collaboration? How willing are the teachers to accept your suggestions regarding their relationship with the students (in cases where there is a problem between the teacher and the student)?

\section{Procedures}

The research was conducted in schools where final year students of Pedagogy studies had their internship done. They had the role of assistant researchers. After a thorough preparation during which students received guidance on a professional approach to research and interviewing, they had the opportunity to talk with school counsellors about their practice. Data collection took place from 2015 to 2018 , and interviews were conducted at the time of student internship. In this way, students had the opportunity to become familiar with the practice of counselling work at school, which was otherwise prevented due to the protection of counsellees' privacy. Before starting, the interviewees were informed about the purpose of 
the interview, the ethical standards of the research regarding the confidentiality of the findings and the voluntariness to participate in the interview. The duration of the interview was not limited given that the assistant researchers were taking the interview notes and the average interview duration was approximately 45 minutes. Respondents were given the opportunity to look at the veracity of the notes and, if they deemed it necessary, add some parts.

\section{Data Analysis}

The data obtained from the research were processed using qualitative thematic analysis (Braun \& Clarke, 2006) which included: familiarizing with the material, generating initial codes, identifying topics and subtopics, recoding data and refining topics, final naming of the topics, drafting reports (final analysis and interpretation, backed by some of the original responses for illustration).

\section{Results of Research}

\section{Involvement of teachers in the counselling process}

A wide range of answers was obtained during conversation about this topic. Most respondents point out that teachers are often part of the counselling with students and that the best interests of the student themselves are always the focus when engaging in this process. School counsellors also pointed out that each counselling situation is specific and it dictates whether and in which stage of the counselling the teacher will be involved. For better transparency of the data obtained, Table 1 presents answers to the questions of how often and in which cases teachers were involved in this process.

Table 1. Involvement of teachers in the counselling process

\begin{tabular}{lll}
\hline $\begin{array}{c}\text { Do you involve } \\
\text { teachers in the } \\
\text { counselling } \\
\text { process? }\end{array}$ & f & In which cases do you involve teachers in the counselling process? \\
\hline Yes, always & 21 & $\begin{array}{l}\text { - when they are class teachers } \\
\text { - when I need information about the student from the teacher } \\
\end{array}$ \\
& - always, except in cases that require discretion \\
\hline Yes & $\begin{array}{l}\text { - counselling regarding conducting lessons } \\
\text { - learning difficulties } \\
\end{array}$ \\
& - the need for intensive pedagogical work with certain students or \\
& entire class \\
& - when they are teacher trainees \\
\hline
\end{tabular}




\begin{tabular}{|c|c|c|}
\hline $\begin{array}{l}\text { Do you involve } \\
\text { teachers in the } \\
\text { counselling } \\
\text { process? }\end{array}$ & f & In which cases do you involve teachers in the counselling process? \\
\hline $\begin{array}{l}\text { It depends on the } \\
\text { situation }\end{array}$ & 24 & $\begin{array}{l}\text { - problems between student(s) and teacher } \\
\text { - problematic behavior and/or learning difficulties } \\
\text { - complaints on teacher's performance } \\
\text { - planning and conducting workshops within group counselling } \\
\text { - working with students with disabilities }\end{array}$ \\
\hline In most cases & 10 & $\begin{array}{l}\text { - at the beginning of counselling work and during subsequent moni- } \\
\text { toring of student behavior } \\
\text { - planning and implementing various school projects }\end{array}$ \\
\hline Rarely & 1 & $\begin{array}{l}\text { - „Rarely. If the case is related to the subject teacher (and most often it } \\
\text { is not)” }\end{array}$ \\
\hline
\end{tabular}

\section{Teachers' openness for cooperation}

The interview was deepened through the question about teachers' openness to cooperation and willingness to accept the educators' suggestions. Almost all respondents said that teachers are ready to cooperate always or in most cases, while some pedagogues pointed out that teachers are initially less open, but that "after a couple of conversations the situation changes". An interesting observation was made by several respondents who claim that lower grade teachers are more willing to cooperate than teachers that teach in higher grades. Despite the fact that almost all the respondents indicated that teachers are willing to cooperate, there were several factors that determined whether they were really ready to accept the counsellor's suggestion:

1. Teachers' personality. According to the respondents, the authoritarian type of teacher tends to accept suggestions with more difficulty. (e.g.: "A teacher with an authoritarian upbringing style will often, despite my suggestions, still come from a position of power, criticizing and condemning while not giving adequate support to the child".). Some respondents stated that the willingness to accept what is suggested also depends on his/her vanity, and that some teachers even get offended if counsellors suggest something to them.

2. Teachers' professional orientation. Respondents stated that teachers from lower grades, teachers of social groups of subjects, as well as novice teachers are more willing to accept suggestions. Particularly interesting is the observation of one respondent who stated: "In my experience, there is a big difference in the pedagogical preparedness of lower grade teachers and subject teachers. The former quickly understand the proposed measures and imple- 
ment the plan more successfully. Since they work with students in all classes during the entire school day, they know them much better".

3. The counsellors' skills and the content of the suggestions they make. According to the respondents, "suggestions and advice must be precise and concise without unnecessary words, professional", focused on actions and not on personality, and related to a specific problem. Some respondents said that the influence of school counsellors also depends on their position and experience (e.g.: "Approach to every teacher is different, that way I try to win them over for establishing collaboration.").

4. Lack of teacher's perseverance in honoring the agreement. A group of respondents indicated that the teachers readily accepted the suggestions, but the problem lies in the realization of the agreement. The reasons for the lack of persistence in the implementation of what is agreed range from the fact that teachers do not recognize the problem, implement the agreement "to the extent suitable to them" or "don't understand the essence, they are putting in the effort but they do not have the capacity to carry it out appropriately".

\section{Discussion}

Given the many benefits of collaboration with different relevant subjects during the counselling process, this research was aimed to examine the actual presence and quality of collaboration between counsellors and teachers. Results of this study show that teachers are generally involved in counselling work, which is also supported by some previous research which indicate that school counsellors perceive that it is most important to collaborate with teachers because they most directly impact student education (Gibbson, Diambra \& Buchanan, 2010). However, the results have shown that the intensity of their involvement varies depending on the teacher's role and the specific nature of the situation at hand. Teachers who serve as class teachers are often an indispensable part of counselling with students. Given that it is important to collect as much relevant information about the student as possible in order to carry out the advisory work effectively (Zuković, 2017), class teachers, as those who collaborate with students the most, represent a very valuable asset to the counsellor.

In this research, participants did recognize teachers as a valuable source of information about counsellees especially at the beginning of the counselling process, as well as a great resource for following up on students' progress after the counselling process. Other authors (Sink, 2003), recognized that involving 
teachers, as well as other relevant subjects, in the counselling process can have a positive effect on academic achievement of students. This is also confirmed by some earlier research that examined the implementation of a comprehensive school counselling program, related to multisystemic guidance in counselling, which is such practice where counsellors must know and respect the various interconnected student-related subsystems (Keys \& Bemak, 1997). According to some authors (Dixon et al., 2008), the benefits of collaboration between counsellors and teachers can: increase teacher competencies in working with students from vulnerable groups, strengthen the connection between relevant subjects in the school environment, support parental involvement in school life and maximize use of limited school resources.

Respondents noted that teachers' openness to accepting suggestions from counsellors depends on several factors. As the most frequent response, the respondents stated that openness is highly dependent on the teacher's personality. Some respondents pointed out that in this domain the greatest obstacle to successful cooperation and acceptance of constructive criticism is teachers' vanity. It is interesting to note that social science subject teachers and teachers in lower grades of elementary school are more open to cooperation than teachers of the natural science group of subjects. A potential explanation for this research finding may lie in the characteristics of initial preparation of teachers in Serbia. The teachers who teach social science subjects in their initial education take more pedagogical, psychological and didactic courses, in comparison to teachers of natural science group of subjects.

Although the presented research results show the presence of collaboration between school counsellors and teachers, it is necessary to highlight certain methodological limitations and implications for further research. The main limitation of this study is caused by the use of a convenience sample considering that participants are exclusively from Northern Serbia, which prevents generalization. Also, in order to explore this phenomenon further, it would be important to examine teachers' experiences regarding this topic.

\section{Conclusions}

The obtained findings on the cooperation between school counsellors and teachers can be viewed as a contribution to the postulate on the importance of developing effective partnership so that school counselling will become more comprehensive and directed to the entire development of students and school as 
a whole (Zuković, 2017). The role of the school counsellor is crucial and unique in the process of promoting and facilitating collaboration between all participants of school life (American School Counselor Association, 2012), and these professionals serve as a "bridge" between all those participants (Bryan \& Henry, 2012). Therefore, counsellors are expected to utilize their competencies in order to win the cooperation of those individuals in the school who initially refuse to do so. Specifically, promoting teamwork with teachers allows for a higher level of commitment to achieve set goals and make shared decisions, create a climate of support, understanding and trust, as well as increasing the morale among staff which then contributes to effective schooling (Hernández \& Seem, 2004). Also, the role of the school counsellor should be focused on helping the teacher know how to work, and not what to do (Zuković, 2017). In line with this approach, taking a role of "critical friend" is a good way for the counsellor to collaborate effectively with the teaching staff. School counsellors, considering their expertise, can even impart services such as developing, leading, and maintaining peer support groups for teachers, in which they can discuss any problems they have in their practice and reflect on the work they've been doing (Pathirana, 2015). That way the counsellor helps his or her colleagues become "reflexive practitioners", but also to overcome certain situations that can lead to "professional burnout" syndrome (Hanley, 2017), which is often present among professionals working in schools. Considering all of the above, developing partnership with the teachers, who have the most intense contacts with the student, can possibly increase the quality of the counselling itself.

\section{Acknowledgements}

This paper is an output of the science projects 'Quality of educational system of Serbia in the European perspective' (179010) and 'Digital media technology and socio-educational changes' (47020), financed by the Ministry of Education, Science and Technological Development of the Republic of Serbia.

\section{References}

American School Counselor Association. (2012). ASCA national model: A framework for school counseling programs. American School Counselor Association.

Bor, R., Ebner-Landy, J., Gill, S., \& Brace, C. (2002). Counselling in schools. London: SAGE Publications Ltd..

Bovbjerg, K.M. (2006). Teams and Collegiality in Educational Culture. European Educational Research Journal, 5(3-4), 244-253. https://doi.org/10.2304/eerj.2006.5.3.244 
Braun, V., \& Clarke, V. (2006). Using thematic analysis in psychology. Qualitative Research in Psychology, 3(2), 77-101.

Bryan, J., \& Henry, L. (2012). A Model for Building School-Family-Community Partnerships: Principles and Process. Journal of Counseling \& Development, 90(4), 408-420. https://doi.org/10.1002/j.1556-6676.2012.00052.x

Chan, D.W. (2000). Brief Intervention for School Problems: A Practical Approach for Hong Kong Teachers. Asian Journal of Counselling, 7(1), 65-83.

Clark, M.A., \& Amatea, E. (2004). Teacher Perceptions and Expectations of School Counselor Contributions: Implications for Program Planning and Training. Professional School Counseling, 8(2), 132-140.

Dixon, A.L., DeVoss, J.A., \& Davis, E.S. (2008). Strengthening Links between the Levels: School Counselor Collaboration for Successful Student Transitions. Journal of School Counseling, 6(21), 1-33.

Dixon, S., \& Chiang, C.-M. (2019). Promoting Reflexivity and Reflectivity in Counselling, Education, and Research. In: 2018 Canadian Counselling Psychology Conference (15-31). Winnipeg, MA: Canadian Counselling and Psychotherapy Association, 2018.

Eatough, V., \& Smith, J.A. (2008). Interpretative Phenomenological Analysis. In C. Willig \& W.S. Rogers (Eds.), The SAGE Handbook of Qualitative Research in Psychology (pp. 179-194). London: SAGE Publications Ltd.

Gibson, M.M., Diambra, J.F., \& Buchanan, D.K. (2010). School counselors perceptions and attitudes about collaboration. Journal of School Counseling, 8(34), 1-28.

Hanley, T. (2017). Supporting the emotional labour associated with teaching: Considering a pluralistic approach to group supervision. Pastoral Care in Education, 35(4), 253-266. https://doi.org/10.1080/02643944.2017.1358295

Hernández, T.J., \& Seem, S.R. (2004). A Safe School Climate: A Systemic Approach and the School Counselor. Professional School Counseling, 7(4), 256-262.

Juul, J., \& Jensen, H. (2017). Relational competence: Towards a new culture of education. Germany: Edition + plus.

Keys, S.G., \& Bemak, F. (1997). School-Family-Community Linked Services: A School Counseling Role for Changing Times. The School Counselor, 44(4), 255-263.

Pathirana, B.D.D. (2015). Mapping out the potential role for Sri Lankan school counselor: An exploratory study. International Journal of Advanced Research, 3(5), 609-618.

Przybylska, I. (2011). Teachers' role perception. The New Educational Review, 26(4), 85-95.

Savin-Baden, M., \& Major, C.H. (2012). Qualitative research: The essential guide to theory and practice. Oxford: Routledge.

Shah, M. (2012). The Importance and Benefits of Teacher Collegiality in Schools - A Literature Review. Procedia - Social and Behavioral Sciences, 46, 1242-1246. https://doi. org/10.1016/j.sbspro.2012.05.282

Sink, C. (2003). Improving Academic Achievement in Primary Students Through a Systemic Approach to Guidance and Counseling (Research Report No. 4; pp. 1-24). Washington School Research Center. https://www.umass.edu/schoolcounseling/uploads/WSRC.pdf 
Vernon, A., \& Kottman, T. (2009). Counseling theories. Practical applications with children and adolescents in school settings. Love Publishing Company.

Zuković, S., \& Slijepčević, S. (2019). Counselling competences from the perspective of school pedagogues. Zbornik Instituta Za Pedagoska Istrazivanja, 51(1), 198-237. https:// doi.org/10.2298/ZIPI1901198Z

Zuković, S. (2017). Savetodavni rad u institucijama vaspitanja i obrazovanja - teorijski i praktični aspekti [Counseling in the institution of education and upbringing - theoretical and practical aspects]. Novi Sad: Filozofski fakultet.

Zuković, S., \& Slijepčević, S. (2020). Counselling Elementary School Students-Experiences of School Counsellors from Serbia. Journal of Psychologists and Counsellors in Schools, 1-13. https://doi.org/10.1017/jgc.2020.15 